\title{
Evaluation of family history as a risk factor and screening tool for detecting undiagnosed diabetes in a nationally representative survey population
}

Susan Hariri, $P h D^{1,2}$ Paula W. Yoon, $S c D^{1,2}$ Ramal Moonesinghe, $P h D^{2}$ Rodolfo Valdez, $P h D^{3}$, and Muin J. Khoury, $M D, P h D^{2}$

\begin{abstract}
Purpose: We examined the utility of a three-level familial risk stratification system as a screening tool for diabetes in a nationally representative sample of the U.S. adult population. Methods: National Health and Nutrition Examination Survey data were used to assess the prevalence and distribution of familial risk for diabetes, the association between three levels of familial risk and undiagnosed diabetes, and the use of familial risk as a screening tool for diabetes, alone and in combination with body mass index and age. Results: The prevalence of undiagnosed diabetes was $3 \%$ and increased with increasing familial risk (average $=2 \%$, moderate $=4 \%$, high $=$ $10 \%$ ). High familial risk was significantly associated with undiagnosed diabetes (adjusted odds ratio $=4.6 ; 95 \%$ confidence interval: 1.9-11.3). The use of a three-tiered familial risk stratification for diabetes screening yielded higher specificity $(94 \%)$ and positive predictive value $(9.9 \%)$ for high familial risk than body mass index $\geq 25$ (specificity $=38 \%$, positive predictive value $=4.2 \%$ ). High familial risk and body mass index $\geq 25$ combined had higher specificity (97\%) and positive predictive value (13.4\%); the addition of age $\geq 45$ years further improved positive predictive value $(21.0 \%)$ without reducing specificity. Conclusions: There was a strong and proportional association between familial risk and undiagnosed diabetes, suggesting that a three-tiered assessment of familial diabetes risk may increase the effectiveness of diabetes screening. Genet Med 2006:8(12):752-759.
\end{abstract}

Type 2 diabetes mellitus (T2DM) is a common and costly disease in the United States and worldwide. ${ }^{1-4}$ According to estimates based on 1999 to 2000 survey data, 16.7 million U.S. adults aged 20 years or older $(8.3 \%$ of the U.S. adult population) had diabetes, but only $71 \%$ were aware of their disease status. ${ }^{4}$ T2DM is an insidious disease with prolonged asymptomatic stages that can be detected through available diagnostic tests. ${ }^{5}$ However, the frequent presence of characteristic microvascular changes at the time of diagnosis suggests a 2- to 10 -year lag between disease onset and eventual diagnosis in many cases. ${ }^{1,5}$ The large number of U.S. adults with undiagnosed T2DM demonstrates the need for earlier identification of the disease, especially given mounting evidence that diabetes can be prevented or delayed among high-risk adults with timely and intensive intervention. ${ }^{6,7}$ Unfortunately, there is currently no consensus regarding mass screening for diabetes among asymptomatic populations. ${ }^{5}$ Moreover, although most

\footnotetext{
From the ${ }^{I}$ Office of Workforce and Career Development, Centers for Disease Control and Prevention; ${ }^{2}$ Office of Genomics and Disease Prevention, Centers for Disease Control and Prevention; and ${ }^{3}$ Division of Diabetes Translation, National Center for Chronic Disease Prevention and Health Promotion, Centers for Disease Control and Prevention, Atlanta, Georgia.

Susan Hariri, PhD, 4770 Buford Highway, Mailstop K-89, Atlanta, GA 30341.

Submitted for publication June 26, 2006.

Accepted for publication September 13, 2006.

DOI: 10.1097/01.gim.0000250205.73963.f3
}

medical organizations, including the U.S. Preventive Services Task Force, the American Diabetes Association, and other national and international societies, recommend opportunistic diabetes screening in certain high-risk groups, their screening guidelines are often inconsistent and ambiguous. ${ }^{5}$ For example, although obesity, membership in certain racial/ethnic groups, and a family history of diabetes are indicators of high risk in the screening guidelines of most organizations, these risk factors are often poorly defined, and the definitions vary by organization. Thus, better characterization of high-risk individuals remains a clinical and public health priority.

A family history of diabetes is a known risk factor for diabetes and a criterion for screening in most current guidelines. ${ }^{5,8-10}$ However, the complexity of family history, which represents a combination of genetic and environmental risk factors and their interactions, is often overlooked in defining familial risk of disease. Typically, most family history-based screening is based on a crude definition of the presence of diabetes in any family member, irrespective of the degree or type of relatedness or number of affected relatives. ${ }^{8,11-14}$ More refined familial risk stratification may have the potential to provide a valid and reliable screening tool with better resolution of disease risk while remaining simple and potentially cost-effective. Family history information can be used to classify individuals or groups of people according to different levels of familial risk such as average, moderate, and high. Further, this more refined assessment of familial risk can be combined with assessments of other known risk factors such as obesity and age to 
develop an even more robust family history-based screening tool. Finally, family history can be used more broadly as a populationbased screening tool for identifying groups of people at high risk for the disease that can benefit from a more thorough clinical evaluation. Such targeted screening could result in more efficient allocation of resources and more effective policies and practice guidelines.

The purpose of this study was to examine the utility of a three-level familial risk stratification system as a screening tool for diabetes in a nationally representative sample of the U.S. adult population. The specific aims were to describe the prevalence and distribution of various levels of familial risk for diabetes, to examine the magnitude of the association between familial risk categories and diagnosed and undiagnosed diabetes, and to evaluate the utility of family history as a screening tool, both alone and in combination with two other important risk factors for the disease: overweight (body mass index [BMI] $\geq 25$ ) and advanced age ( $\geq 45$ years).

\section{MATERIALS AND METHODS}

\section{Population}

The data used in this study are from the 1999 to 2002 National Health and Nutrition Examination Survey (NHANES), the most recent 4-year period for which NHANES data are available. NHANES is an annual survey designed to provide nationally representative estimates of the health and nutritional status of the civilian noninstitutionalized U.S. population. ${ }^{15}$ A complex probability sample design is used to produce unbiased estimates that are representative of the U.S. population. NHANES data are based on personal interviews and physical examinations of survey participants, the latter of which include biologic measurements such as fasting plasma glucose (FPG) levels. As such, NHANES is the only nationally representative survey that can estimate the prevalence of diagnosed diabetes (self-reported) and undiagnosed diabetes (measured). During this time period, $83 \%$ of all eligible participants were interviewed, and 78\% received a physical examination.

\section{Sample}

Data from annual surveys conducted during the 4-year period from 1999 to 2002 were combined to represent a single survey as recommended by the NHANES analytic guidelines. ${ }^{16}$ The study sample consisted of 9696 nonpregnant adult respondents, aged 20 years or more, who were interviewed, 8511 of whom underwent a physical examination. To estimate the prevalence of undiagnosed diabetes, we further limited the sample to 3823 participants who were randomly selected to receive an FPG measurement. This subsample is similar to the original sample in all characteristics and is weighted to maintain representativeness of the U.S. population.

\section{Variable definition}

Diabetes status was ascertained as follows: Respondents who reported having been told by a doctor or a health professional that they had diabetes or "sugar diabetes" other than during pregnancy were classified as having diagnosed diabetes $(\mathrm{n}=$
991); those with an FPG level $126 \mathrm{mg} / \mathrm{dL}$ or greater but no medical history of diabetes were classified as having undiagnosed diabetes $(n=150)$.

Demographic information was collected at the time of the interview. Age, income, and education were categorized to facilitate comparison with U.S. Census data. Race categories were based on NHANES classifications. Participants' BMI, calculated as weight in kilograms divided by height in meters squared $\left(\mathrm{kg} / \mathrm{m}^{2}\right)$, was based on measurements recorded during the physical examination, and participants were divided into three categories (normal weight or below, overweight, and obese) on the basis of their BMI. ${ }^{17}$

Participants' family history of diabetes was ascertained by the following questions: "Including living and deceased, were any of $\{\mathrm{SP} /$ your $\}$ biological, that is, blood relatives including grandparents, parents, brothers, sisters ever told by a health professional that they had diabetes?" For "yes" responses, participants were asked to specify which of the following biologic relatives were affected: mother, father, mother's mother, mother's father, father's mother, father's father, brother, sister, and other.

By using the number and type of affected relatives, we classified respondents into three familial risk levels according to the algorithm that follows, adapted from Scheuner et al. ${ }^{9}$

High: At least ...

- Two first-degree relatives (parents or siblings) with diabetes

- One first-degree and two second-degree relatives (grandparents) with diabetes from same lineage

Moderate: Only ...

- One first-degree and one second-degree relative with diabetes

- One first-degree relative with diabetes

- Two second-degree relatives with diabetes from same lineage

Average:

- Only one second-degree relative with diabetes from one or both sides of family

- No family history of diabetes

This classification has been proposed by us and others as a standard for a three-tiered familial risk stratification scheme. ${ }^{9,18,19}$ In this context, the term "average" risk is used to indicate a baseline population risk of developing diabetes with minimal or no familial risk of diabetes.

\section{Statistical analyses}

All estimates were weighted using fasting morning sample weights to obtain unbiased estimates following NHANES analytic guidelines. ${ }^{20}$ Statistical analyses were performed in SAS 9.1 (SAS Institute Inc., Cary, NC) and SAS-Callable SUDAAN (Research Triangle Institute, Research Triangle Park, NC) using procedures that calculate appropriate standard errors on the basis of the multistage stratified survey sampling design. 
Overall and stratified prevalence estimates and their 95\% confidence intervals (CIs) were calculated to examine significant differences and to highlight the variability in estimates in the smaller subgroups investigated. Multivariable logistic regression was used to examine associations between familial risk and various risk factors and diagnosed and undiagnosed diabetes. Because the odds ratio (OR) tends to overestimate, and thus is not a good approximation of the relative risk when the outcome of interest is common, ${ }^{21}$ marginal predicted probabilities from the logistic models were used to obtain relative risks for comparison with the ORs. The analytic validity of age, $\mathrm{BMI}$, and family history as screening tools for diabetes was evaluated.

\section{RESULTS}

\section{Prevalence of family history by risk level, diabetes, and other risk factors}

Only $2 \%$ of respondents refused to answer, and less than $1 \%$ indicated a lack of knowledge when asked about the history of diabetes among their blood relatives, suggesting a high level of awareness of the disease among family members. Approximately half (48.3\%, 95\% CI: 46.3-50.2) of all respondents reported having at least one blood relative with diabetes. This proportion was higher among those with undiagnosed diabetes (59.3, 95\% CI: 51.1-67.5) and highest among those with diagnosed diabetes (75.8, 95\% CI: 72.5-79.2).

Table 1

Distribution of selected characteristics of U.S. adults overall and by familial risk for diabetes, NHANES 1999 to 2002

\begin{tabular}{|c|c|c|c|c|}
\hline \multirow[b]{2}{*}{ Characteristic } & \multirow[b]{2}{*}{ Overall \% (95\% CI) } & \multicolumn{3}{|c|}{ Familial risk strata } \\
\hline & & Average \% (95\% CI) & Moderate \% (95\% CI) & High \% $(95 \% \mathrm{CI})$ \\
\hline \multicolumn{5}{|l|}{ Sex } \\
\hline Male & $48.8(47.8-49.7)$ & $50.0(48.9-51.2)$ & $47.3(45.0-49.6)$ & $40.4(35.9-44.9)$ \\
\hline Female & $51.2(50.3-52.2)$ & $50.0(48.8-51.1)$ & $52.7(50.4-55.0)$ & $59.6(55.1-64.1)$ \\
\hline \multicolumn{5}{|l|}{ Age $(y)$} \\
\hline $20-39$ & $38.7(37.0-40.5)$ & $41.9(39.7-44.1)$ & $33.8(31.2-36.5)$ & $22.0(18.1-26.0)$ \\
\hline $40-59$ & $38.4(36.9-40.0)$ & $36.0(33.9-38.1)$ & $42.5(40.1-44.9)$ & $49.3(45.2-53.5)$ \\
\hline $60+$ & $22.9(21.6-24.2)$ & $22.1(20.6-23.6)$ & $23.7(21.4-25.9)$ & $28.7(24.0-33.3)$ \\
\hline \multicolumn{5}{|l|}{ Race } \\
\hline White/non-Hispanic & $71.1(67.5-74.7)$ & $73.0(69.4-76.7)$ & $69.3(65.8-72.7)$ & $57.3(49.3-65.4)$ \\
\hline Black/non-Hispanic & $10.6(8.2-13.0)$ & $9.7(7.6-11.9)$ & $11.7(8.6-14.8)$ & $16.8(12.1-21.5)$ \\
\hline Mexican & $6.9(5.2-8.6)$ & $6.4(5.0-7.9)$ & $7.8(5.6-10.0)$ & $9.0(5.5-12.6)$ \\
\hline Other & $11.3(7.6-15.0)$ & $10.8(7.1-14.5)$ & $11.2(7.5-15.0)$ & $16.8(9.7-24.0)$ \\
\hline \multicolumn{5}{|l|}{ Income } \\
\hline$<25 \mathrm{k}$ & $27.8(25.0-30.7)$ & $27.4(24.5-30.3)$ & $27.1(22.9-31.3)$ & $35.1(30.3-39.8)$ \\
\hline $25-54 \mathrm{k}$ & $32.2(30.3-34.2)$ & $30.9(29.0-32.8)$ & $34.8(30.4-39.3)$ & $36.7(31.9-41.6)$ \\
\hline$\geq 55 \mathrm{k}$ & $40.0(36.5-43.4)$ & $41.7(37.9-45.6)$ & $38.1(34.0-42.1)$ & $28.2(22.6-33.9)$ \\
\hline \multicolumn{5}{|l|}{ Education } \\
\hline$<$ High school & $19.5(17.5-21.6)$ & $18.2(15.7-20.8)$ & $21.0(18.3-23.7)$ & $28.3(19.6-37.1)$ \\
\hline High school diploma/GED & $25.4(23.7-27.1)$ & $25.8(23.7-27.9)$ & $22.6(18.9-26.3)$ & $31.8(23.5-40.1)$ \\
\hline$>$ High school & $55.0(51.7-58.3)$ & $56.0(52.5-59.5)$ & $56.4(51.2-61.6)$ & $39.9(32.8-47.0)$ \\
\hline \multicolumn{5}{|l|}{ Insurance } \\
\hline Yes & $82.6(80.8-84.4)$ & $82.4(80.6-84.1)$ & $82.1(79.3-84.8)$ & 86.7 (83.0-90.5) \\
\hline No & $17.4(15.6-19.2)$ & $17.6(15.8-19.4)$ & $17.9(15.2-20.7)$ & $13.3(9.5-17.0)$ \\
\hline \multicolumn{5}{|l|}{ BMI } \\
\hline $0-24$ & $35.2(33.4-36.8)$ & $38.7(36.5-40.8)$ & $27.7(25.4-29.7)$ & $24.6(19.8-29.3)$ \\
\hline $25-29$ & $34.7(33.0-36.4)$ & $34.6(32.4-36.7)$ & $35.7(33.4-37.9)$ & $32.8(27.8-37.8)$ \\
\hline$\geq 30$ & $30.0(28.3-32.1)$ & $26.7(24.8-28.8)$ & 36.7 (33.9-39.7) & $42.6(37.3-48.0)$ \\
\hline Total & & $70.2(68.8-71.6)$ & $23.0(22.0-24.1)$ & $6.8(6.1-7.5)$ \\
\hline
\end{tabular}

NHANES, National Health and Nutrition Examination Survey; CI, confidence interval; GED, General Equivalency Diploma; BMI, body mass index. 
Table 1 displays the distribution of select demographic characteristics and other diabetes risk factors in the total population overall, as well as stratified by familial risk. On the basis of the familial risk stratification criteria provided above, $7 \%$ of participants were classified as being at high risk for diabetes, $23 \%$ as being at moderate risk, and $70 \%$ as being at average risk. The results showed that women were more likely to be in the moderate- and high-risk groups than men, that those in the 40- to 59-year age category were more likely than those in other age groups to be in the moderate- and high-risk groups, that those in the 20- to 39-year age category were most likely to be in the average-risk category, and that the percentage of whites in the high-risk group (57\%) was less than the percentage of whites in the total survey population (71\%). In addition, the results indicated that people with low income and low education were more likely to be in the moderate- and high-risk groups, and that more than $80 \%$ of survey respondents reported having some type of insurance irrespective of familial risk. The overall prevalence of obesity was high $(30 \%)$ but was even higher among those with moderate and high familial risk of diabetes ( $37 \%$ and $42 \%$, respectively).

The prevalence of diagnosed diabetes (self-reported) was estimated to be $7 \%$ in the total population (Table 2), whereas $3 \%$ of nonpregnant respondents without a medical history of diabetes were found to have an FPG level of $126 \mathrm{mg} / \mathrm{dL}$ or greater, indicating undiagnosed diabetes (Table 3). Also, the prevalence of both diagnosed and undiagnosed diabetes increased attendant with increasing familial risk. The prevalence

Table 2

Prevalence of diagnosed diabetes among U.S. adults, by selected characteristics and familial risk, NHANES 1999 to 2002

\begin{tabular}{|c|c|c|c|c|}
\hline \multirow[b]{2}{*}{ Characteristic } & \multirow[b]{2}{*}{ Overall \% (95\% CI) } & \multicolumn{3}{|c|}{ Familial risk strata } \\
\hline & & Average \% (95\% CI) & Moderate \% (95\% CI) & High \% $(95 \%$ CI $)$ \\
\hline \multicolumn{5}{|l|}{ Sex } \\
\hline Male & $6.7(5.9-7.5)$ & $3.9(3.3-4.5)$ & $10.6(8.4-12.8)$ & $27.2(21.7-32.7)$ \\
\hline Female & $6.6(5.7-7.4)$ & $3.0(2.4-3.6)$ & $11.2(9.3-13.1)$ & $24.0(19.3-28.6)$ \\
\hline \multicolumn{5}{|l|}{ Age (y) } \\
\hline $20-39$ & $1.7(1.1-2.3)$ & $1.0(0.4-1.5)$ & $3.2(1.7-4.8)$ & $9.2(2.3-16.0)$ \\
\hline $40-59$ & $6.6(5.6-7.6)$ & $2.8(2.1-3.5)$ & $10.0(7.6-12.4)$ & $25.2(20.4-30.0)$ \\
\hline $60+$ & $15.1(13.8-16.4)$ & $9.3(8.2-10.4)$ & $23.5(20.0-27.0)$ & $37.8(32.6-43.0)$ \\
\hline \multicolumn{5}{|l|}{$\operatorname{Race}^{a}$} \\
\hline White/non-Hispanic & $5.7(5.0-6.4)$ & $3.2(2.7-3.7)$ & $9.4(7.8-11.0)$ & $24.1(19.7-28.6)$ \\
\hline Black/non-Hispanic & $10.3(8.7-11.9)$ & $5.4(4.2-6.5)$ & $15.2(12.1-18.4)$ & $27.8(22.3-33.3)$ \\
\hline Mexican & $6.7(5.6-7.8)$ & $3.2(2.3-4.1)$ & $9.2(6.6-11.7)$ & $25.6(19.4-31.9)$ \\
\hline \multicolumn{5}{|l|}{ Income } \\
\hline$<25 \mathrm{k}$ & $10.2(8.9-11.6)$ & $6.1(4.8-7.4)$ & $14.0(11.1-20.6)$ & $33.8(28.5-39.1)$ \\
\hline $25-54 k$ & $7.0(5.6-8.3)$ & $3.1(2.2-4.1)$ & $11.2(9.0-13.4)$ & $26.9(18.1-35.7)$ \\
\hline$\geq 55 \mathrm{k}$ & $3.6(2.9-4.2)$ & $2.0(1.4-2.6)$ & $6.8(4.2-9.3)$ & $12.9(6.7-19.0)$ \\
\hline \multicolumn{5}{|l|}{ Education } \\
\hline$<$ High school & $11.1(9.2-13.0)$ & $6.2(4.4-8.1)$ & $16.3(11.3-21.3)$ & $30.3(17.5-43.1)$ \\
\hline High school diploma/GED & $6.9(5.8-8.0)$ & $3.3(2.0-4.7)$ & $10.0(6.4-13.7)$ & $29.0(22.5-35.5)$ \\
\hline$>$ High school & $5.5(4.3-6.7)$ & $2.9(2.1-3.7)$ & $9.3(6.4-12.2)$ & $25.0(14.4-35.7)$ \\
\hline \multicolumn{5}{|l|}{ Insurance } \\
\hline Yes & $7.2(6.5-7.9)$ & $3.8(3.3-4.3)$ & $11.7(9.9-13.4)$ & $26.3(0.0-82.3)$ \\
\hline No & $3.9(2.9-4.9)$ & $2.0(1.2-2.7)$ & $6.3(3.9-8.7)$ & $18.9(12.4-25.5)$ \\
\hline \multicolumn{5}{|l|}{ BMI } \\
\hline $0-24$ & $3.0(2.2-3.9)$ & $1.6(1.0-2.2)$ & $6.2(3.3-9.0)$ & $14.9(9.8-20.0)$ \\
\hline $25-29$ & $5.8(4.7-6.9)$ & $3.4(2.6-4.3)$ & $8.9(5.8-12.1)$ & $19.4(12.7-26.2)$ \\
\hline$\geq 30$ & $11.0(9.8-12.2)$ & $5.5(4.2-6.8)$ & $15.6(13.0-18.1)$ & $33.2(28.2-38.1)$ \\
\hline Total & $6.7(6.0-7.3)$ & $3.5(3.0-3.9)$ & $10.9(9.5-12.3)$ & $25.3(22.0-28.6)$ \\
\hline
\end{tabular}

NHANES, National Health and Nutrition Examination Survey; CI, confidence interval; GED, General Equivalency Diploma; BMI, body mass index.

a" Other" race category excluded because of small sample sizes. 
Table 3

Prevalence of undiagnosed diabetes ${ }^{a}$ among U.S. adults, by selected characteristics and familial risk, NHANES 1999 to 2002

\begin{tabular}{|c|c|c|c|c|}
\hline \multirow[b]{2}{*}{ Characteristic } & \multirow[b]{2}{*}{ Overall \% (95\% CI) } & \multicolumn{3}{|c|}{ Familial risk strata } \\
\hline & & Average \% (95\% CI) & Moderate \% (95\% CI) & High \% (95\% CI) \\
\hline \multicolumn{5}{|l|}{ Sex } \\
\hline Male & $3.7(2.7-4.8)$ & $3.0(2.0-4.1)$ & $4.3(2.2-6.3)$ & $12.2(3.8-20.7)$ \\
\hline Female & $2.4(1.7-3.1)$ & $1.4(0.8-2.0)$ & $3.8(2.3-5.3)$ & $8.3(3.9-12.8)$ \\
\hline \multicolumn{5}{|l|}{ Age $(y)$} \\
\hline $20-39$ & $0.7(0.0-1.5)$ & $0.5(0.0-1.1)$ & $1.2(0.3-2.0)$ & $3.4(2.5-4.3)$ \\
\hline $40-59$ & $3.5(2.2-4.9)$ & $2.4(1.4-3.4)$ & $4.8(2.2-7.3)$ & $9.2(2.4-16.0)$ \\
\hline $60+$ & $6.8(5.0-8.6)$ & $5.5(3.5-7.4)$ & $7.5(4.5-10.4)$ & $18.9(9.4-28.4)$ \\
\hline \multicolumn{5}{|l|}{ Race $^{b}$} \\
\hline White/non-Hispanic & $3.1(2.3-3.9)$ & $2.5(1.7-3.2)$ & $3.3(1.9-4.7)$ & $11.4(5.2-17.6)$ \\
\hline Black/non-Hispanic & $3.7(2.1-5.2)$ & $1.9(0.3-3.5)$ & $7.7(3.5-12.0)$ & $7.3(2.4-12.2)$ \\
\hline Mexican & $2.0(1.3-2.8)$ & $0.7(0.2-1.3)$ & $2.6(1.4-3.7)$ & $12.2(4.8-19.6)$ \\
\hline \multicolumn{5}{|l|}{ Income } \\
\hline$<25 \mathrm{k}$ & $4.8(2.6-6.9)$ & $4.3(1.7-6.9)$ & $5.6(2.6-8.6)$ & $6.7(2.2-11.3)$ \\
\hline $25-54 \mathrm{k}$ & $3.1(1.6-4.6)$ & $1.3(0.3-2.3)$ & $4.3(1.4-7.2)$ & $18.4(7.3-29.4)$ \\
\hline$\geq 55 \mathrm{k}$ & $1.9(1.2-2.5)$ & $1.3(0.8-1.9)$ & $2.5(0.3-4.8)$ & $6.6(0.0-14.5)$ \\
\hline \multicolumn{5}{|l|}{ Education } \\
\hline$<$ High school & $6.4(4.3-8.5)$ & $5.9(3.3-8.5)$ & $7.4(1.9-12.9)$ & $7.6(1.4-13.8)$ \\
\hline High school diploma/GED & $2.7(0.9-4.5)$ & $1.8(0.0-3.7)$ & $2.3(0.0-5.3)$ & $15.8(0.6-31.0)$ \\
\hline$>$ High school & $2.6(1.4-3.8)$ & $2.0(0.8-3.3)$ & $2.6(1.1-4.2)$ & $9.5(0.0-19.7)$ \\
\hline \multicolumn{5}{|l|}{ Insurance } \\
\hline Yes & $3.0(2.4-3.7)$ & $2.1(1.5-2.7)$ & $4.3(2.9-5.7)$ & $8.8(5.0-12.6)$ \\
\hline No & $3.0(1.7-4.3)$ & $2.3(0.8-3.8)$ & $2.5(0.0-5.1)$ & $19.3(1.2-37.3)$ \\
\hline \multicolumn{5}{|l|}{ BMI } \\
\hline $0-24$ & $0.9(0.4-1.5)$ & $0.7(0.1-1.4)$ & $1.1(0.0-2.4)$ & $3.3(0.0-6.9)$ \\
\hline $25-29$ & $2.8(1.8-3.7)$ & $2.6(1.3-3.9)$ & $3.2(1.0-5.3)$ & $3.3(0.0-7.0)$ \\
\hline$\geq 30$ & $6.0(4.4-7.6)$ & $3.5(1.8-5.1)$ & $7.3(4.7-9.9)$ & $23.2(11.4-35.0)$ \\
\hline Total & $3.1(2.4-3.7)$ & $2.2(1.5-2.9)$ & $4.0(2.8-5.3)$ & $9.9(5.7-14.0)$ \\
\hline
\end{tabular}

NHANES, National Health and Nutrition Examination Survey; CI, confidence interval; GED, General Equivalency Diploma; BMI, body mass index.

${ }^{a}$ As indicated by an FPG level $\geq 126 \mathrm{mg} / \mathrm{dL}$ among those who did not report having been diagnosed with diabetes.

b"Other" race category excluded because of small sample sizes.

of diagnosed diabetes was associated with the level of familial risk among both men and women and across all age, race, income, education, and BMI categories (Table 2).

Similar information for undiagnosed diabetes is summarized in Table 3. As shown, the prevalence of undiagnosed diabetes was associated with the level of familial diabetes risk in both sexes, across all age groups, among non-Hispanic whites and Mexican Americans, across all income categories, and among people who were obese. The prevalence of undiagnosed diabetes was found to be higher among non-Hispanic blacks in the moderate-risk category than among those in the averagerisk category, but no significant difference in risk was seen between those in the moderate- and high-risk categories. Sim- ilarly, prevalence slightly increased only between average- and moderate-risk categories in those with less than a high school education. A slight increasing trend in undiagnosed diabetes was present in the lowest BMI category, but the prevalence was almost the same across familial risk in the overweight group.

\section{Family history as a risk factor for diagnosed and undiagnosed diabetes}

The association between familial risk and self-reported and undiagnosed diabetes was evaluated using separate multivariate logistic regression models selected in accordance with the purposeful model selection method. ${ }^{22}$ The presence of multiplicative interactions was evaluated for diagnosed diabetes, but 
there was insufficient power to detect interaction effects for undiagnosed diabetes.

As shown in Table 4, diagnosed diabetes was strongly associated with having a high-risk family diabetes history $(\mathrm{OR}=7.5$, $95 \%$ CI: $5.4-10.3)$, being aged 60 years or more ( $\mathrm{OR}=10.5,95 \%$ CI: 6.4-17.2), and being aged 40 to 59 years ( $\mathrm{OR}=3.9,95 \% \mathrm{CI}$ : 2.2-7.0). A moderate-risk family history was also significantly associated with diagnosed diabetes ( $\mathrm{OR}=2.8,95 \% \mathrm{CI}: 2.1-3.7$ ), as were male sex and nonwhite race. No significant interactions were found between family history and other risk factors. The difference in magnitude between predicted risk ratios obtained from the marginal probabilities and $\mathrm{OR}$ estimates was comparable at a lower prevalence and increased with increasing prevalence, as expected.

As shown in Table 5, a high-risk family diabetes history was also significantly associated with the prevalence of undiagnosed diabetes, although the association was not as strong as with diagnosed diabetes. Risk factors strongly associated with undiagnosed diabetes were age ( $\mathrm{OR}=26.4,95 \%$ CI: $5.4-128.9$ among those aged $60-85$ years; $\mathrm{OR}=8.5,95 \%$ CI: $1.8-41.6$

\section{Table 4}

Adjusted $^{a}$ odds ratios, predicted marginal probabilities, and prevalence ratios for diagnosed diabetes among U.S. adults, by selected risk factors, NHANES 1999 to 2002

\begin{tabular}{lcc}
\hline & $\begin{array}{c}\text { Predicted } \\
\text { marginal } \\
\text { Risk factor }\end{array}$ & $\begin{array}{c}\text { Prevalence } \\
\text { ratio }^{b}\end{array}$ \\
\hline
\end{tabular}

Family history

$\begin{array}{lcrc}\text { Average } & \text { Referent } & 3.6 & - \\ \text { Moderate } & 2.8(2.1-3.7) & 8.9 & 2.5 \\ \text { High } & 7.5(5.4-10.3) & 19.1 & 5.3\end{array}$

Sex

$\begin{array}{lccc}\text { Female } & \text { Referent } & 5.6 & - \\ \text { Male } & 1.4(1.2-1.8) & 7.4 & 1.3\end{array}$

Age (y)

$\begin{array}{lcrl}20-39 & \text { Referent } & 1.8 & - \\ 40-59 & 3.9(2.2-7.0) & 6.4 & 3.6 \\ 60+ & 10.5(6.4-17.2) & 13.9 & 7.7\end{array}$

Race

$\begin{array}{lcrl}\text { White/non-Hispanic } & \text { Referent } & 5.8 & - \\ \text { Black/non-Hispanic } & 1.3(1.0-1.6) & 7.0 & 1.2 \\ \text { Mexican } & 1.6(1.3-2.1) & 8.6 & 1.5 \\ \text { Other } & 1.9(1.2-2.9) & 11.4 & 2.0\end{array}$

BMI

\begin{tabular}{llll}
$<25$ & Referent & 4.0 & - \\
$25-29$ & $1.4(0.95-2.1)$ & 5.4 & 1.4 \\
$\geq 30$ & $2.8(1.9-4.2)$ & 9.6 & 2.4 \\
\hline
\end{tabular}

NHANES, National Health and Nutrition Examination Survey; OR, odds ratio; $\mathrm{CI}$, confidence interval; BMI, body mass index.

${ }^{a}$ Adjusted for all demographic variables (in table) and BMI.

${ }^{b}$ Ratio of predicted marginal probabilities.
Table 5

Adjusted ${ }^{a}$ odds ratios, predicted marginal probabilities, and prevalence ratios for undiagnosed diabetes among U.S. adults, by selected risk factors, NHANES 1999 to 2002

\begin{tabular}{lccc}
\hline Risk factor & OR $(95 \%$ CI $)$ & $\begin{array}{c}\text { Predicted marginal } \\
\text { probability }\end{array}$ & $\begin{array}{c}\text { Prevalence } \\
\text { ratio }^{b}\end{array}$ \\
\hline $\begin{array}{c}\text { Avmily history } \\
\text { Moderate }\end{array}$ & Referent & $2.3 \%$ & - \\
High & $4.3(0.7-2.7)$ & $3.0 \%$ & 1.3 \\
Sex & Referent & $8.4 \%$ & 3.7 \\
Female & $3.1(1.7-5.7)$ & $1.7 \%$ & - \\
Male & & $4.6 \%$ & 2.7 \\
Age $($ y) & Referent & & - \\
$20-39$ & $8.5(1.8-41.6)$ & $2.9 \%$ & 7.3 \\
$40-59$ & $26.4(5.4-128.9)$ & $7.9 \%$ & 19.8 \\
$60+$ & & & \\
BMI & Referent & $0.9 \%$ & - \\
$<24$ & $2.8(1.0-8.4)$ & $2.5 \%$ & 6.4 \\
$25-29$ & $7.5(2.4-23.7)$ & $5.8 \%$ & -8 \\
$\geq 30$ & & & \\
\hline
\end{tabular}

NHANES, National Health and Nutrition Examination Survey; OR, odds ratio; CI, confidence interval; BMI, body mass index.

${ }^{a}$ Adjusted for all demographic variables (in table) and BMI.

${ }^{b}$ Ratio of predicted marginal probabilities.

among those aged $40-59$ years) and obesity (OR $=7.5,95 \%$ CI: 2.4-23.7). The association between high-risk family history and undiagnosed diabetes was also significant $(\mathrm{OR}=4.6$, 95\% CI: $1.9-11.3$ ), followed by being male ( $\mathrm{OR}=3.1,95 \% \mathrm{CI}$ : 1.7-5.7), as was the association between undiagnosed diabetes and being overweight ( $\mathrm{OR}=2.8,95 \% \mathrm{CI}: 1.0-8.4)$. Moderate family history was also associated with undiagnosed diabetes, although the association was not statistically significant $(\mathrm{OR}=$ 1.3, 95\% CI: 0.7-2.7). The magnitude of the predicted risk ratios was similar to the OR estimates.

\section{Evaluation of family history as a screening tool for undiagnosed diabetes}

To compare the effectiveness of the three-tier familial risk stratification system with that of a more blunt approach to family risk determination, we collapsed the moderate- and high-risk categories into a single level ("increased familial risk") and compared the results from this two-tier risk scheme with that of the three-tier scheme described above. We similarly examined the effectiveness of using BMI as a dichotomous variable (with the cutoff at $\geq 25$ to correspond with screening guidelines for overweight) to screen for undiagnosed diabetes and of using the two risk factors in combination. Finally, we evaluated the effectiveness of age $\geq 45$ years as an additional screening criterion by limiting the analysis to participants aged 45 to 85 years. As shown in Table 6, when screening was based on a single risk factor, screening for high familial risk had the 
Table 6

Sensitivity, specificity, and positive and negative predictive values of selected diabetes risk factors in screening for undiagnosed diabetes among U.S. adults, NHANES 1999 to 2002

\begin{tabular}{|c|c|c|c|c|}
\hline Risk factor & $\begin{array}{l}\text { Sensitivity } \\
\quad(\%)\end{array}$ & $\begin{array}{l}\text { Specificity } \\
\quad(\%)\end{array}$ & $\begin{array}{l}\text { PVP } \\
(\%)\end{array}$ & $\begin{array}{l}\text { PVN } \\
(\%)\end{array}$ \\
\hline \multicolumn{5}{|l|}{ All adults (aged $20-85$ y) } \\
\hline Increased $^{a}$ familial risk & 47.6 & 73.2 & 5.3 & 97.8 \\
\hline High familial risk & 19.4 & 94.4 & 9.9 & 97.4 \\
\hline $\mathrm{BMI} \geq 25$ & 88.1 & 38.4 & 4.2 & 99.1 \\
\hline $\begin{array}{l}\text { Increased }^{a} \text { familial risk } \\
\text { and } \mathrm{BMI} \geq 25\end{array}$ & 45.2 & 81.4 & 6.9 & 98.0 \\
\hline $\begin{array}{l}\text { High familial risk and } \\
\text { BMI } \geq 25\end{array}$ & 17.6 & 96.5 & 13.4 & 97.5 \\
\hline \multicolumn{5}{|l|}{ Adults aged $45-85$ y } \\
\hline Increased $^{a}$ familial risk & 46.0 & 69.6 & 7.9 & 95.8 \\
\hline High familial risk & 20.5 & 93.4 & 14.9 & 95.4 \\
\hline $\mathrm{BMI} \geq 25$ & 88.7 & 34.2 & 7.0 & 98.2 \\
\hline $\begin{array}{l}\text { Increased familial risk } \\
\text { and } \mathrm{BMI} \geq 25\end{array}$ & 42.0 & 79.7 & 10.4 & 96.1 \\
\hline $\begin{array}{l}\text { High familial risk and } \\
\qquad \mathrm{BMI} \geq 25\end{array}$ & 18.0 & 96.2 & 21.0 & 95.4 \\
\hline
\end{tabular}

NHANES, National Health and Nutrition Examination Survey; PVP, predictive value positive; PVN, predictive value negative; BMI, body mass index.

${ }^{a}$ Includes people considered to be at moderate and high familial risk for diabetes.

highest specificity (94\%) and positive predictive value (9.9\%) followed by results based on screening for "increased" (moderate or high) familial risk ( $73 \%$ specificity, $5.3 \%$ positive predictive) and screening for a BMI greater than 25.0 (38\% specificity, $4.2 \%$ positive predictive value). Conversely, sensitivity was highest for screening by BMI ( $88 \%)$, followed by screening by "increased" familial risk (48\%) and screening by high familial risk (19\%). The negative predictive values for the three screening methods were $97 \%$ for high-risk family history, $98 \%$ for "increased"-risk family history, and 99\% for overweight. Screening by the combination of high family history and overweight had a higher specificity (97\%) and positive predictive value (13.4\%) than screening by either risk factor separately. Screening by "increased" family BMI also had a higher positive predictive value $(6.9 \%)$ than screening by either alone; however, the specificity was slightly lower (81\%). Adding age to the screening criteria increased positive predictive values to $14.9 \%$ for screening by high-risk family history, to $7.9 \%$ for screening by "increased"-risk family history, to $7.0 \%$ for screening by overweight status, to $21.0 \%$ for screening by high-risk family history and overweight status, and to $10.4 \%$ for screening by "increased"-risk family history and overweight status without negatively impacting other measures.

\section{DISCUSSION}

This study is the first to estimate the percentage of U.S. adults in each of three categories of familial risk for diabetes and to demonstrate the potential value of familial risk stratification as a diabetes screening tool on the basis of data from a nationally representative sample of the U.S. adult population. We showed not only that a family history of diabetes is a strong risk factor for both diagnosed and undiagnosed diabetes but also that diabetes prevalence is directly associated with the extent of the family history of diabetes, which also illustrates how the level of risk increases with increasing familial risk. Moreover, these results distinguish family history as a reliable, lowcost, noninvasive, and easy-to-use screening tool, alone or in conjunction with other risk factors for detecting undiagnosed diabetes.

Although having a high-risk family history of diabetes was associated with the prevalence of undiagnosed and diagnosed diabetes, the magnitude of association was smaller for undiagnosed diabetes. One possible explanation for this is that people with diagnosed diabetes are more likely to inquire about their family diabetes history than those who are unaware of their disease status. If so, enhanced public education about the association between one's family diabetes history and one's own diabetes risk could lead more people to assess their family history and, if they find a significant family history of diabetes, to seek diagnostic testing on their own.

The inherent tradeoff between sensitivity (true positive rate) and specificity (true negative rate) requires careful consideration of the goals of any screening test. ${ }^{21,23}$ The objective of using family history and other risk factors for diabetes as a population-based screening tool would be to identify people at high risk for the disease who could then be referred for further diagnostic testing. Therefore, a tool with both a high specificity (a low false-positive rate) and high positive predictive value (Bayesian probability that an individual has diabetes given that they have the risk factor[s]) is most preferred. Our results indicate that restricting screening to people in the highest familial risk group yields more desirable results than screening those in both the moderate and high familial risk groups. They also demonstrate that screening by familial diabetes risk (either for high risk only or for either moderate or high risk) has both higher specificity and higher positive predictive value than screening by BMI, two risk factors recommended by the American Diabetes Association for use to screen for diabetes. ${ }^{5}$ More important, our results indicate that the positive predictive value of family diabetes history in detecting undiagnosed diabetes increases when BMI is used in combination with family history and that it almost doubles (without reducing the test's specificity) when age is also used. It is also important to note the negative predictive value of screening based on a high-risk family history of diabetes (98\%) is almost as high as that of screening based on a BMI of 25.0 or higher (99\%). The results of this analysis thus suggest that diabetes screening guidelines may be more effective if familial risk levels are taken into account. For example, overweight people in the high familial risk category may benefit more from frequent diagnostic screening tests than overweight people in the moderate familial risk category. Moreover, although the sensitivity (true positive rate) of screening based on a three-tiered familial risk stratification is 
lower than that of screening based on a two-tiered scheme, it would only lead to unnecessary testing in a small percentage of the population targeted for screening (3.9\%) relative to the percentage that would be tested if screening were based on a two-tier model of family risk (19.3\%). Although less rigorous screening guidelines for people in the moderate-risk group may seem more efficient and cost-effective, the benefits of following such guidelines must be carefully weighed against the costly complications of uncontrolled diabetes among people whose diabetes may not be detected.

Although the large sample size and use of clinical measurements in NHANES allowed examination of the relationship between three levels of familial risk and the prevalence of undiagnosed diabetes in the U.S. population, the results must be interpreted in the context of important limitations. First, the accuracy of self-reported family histories of diabetes has not been fully investigated in a population-based sample; however, the results of one recent study suggest that most people have a high level of knowledge about the diabetes status of their family members. ${ }^{24}$ Moreover, the long duration of diabetes, the obvious nature and progression of its symptoms, and the lack of stigma associated with the disease are all factors that should reduce errors in self-reported family diabetes histories. Nevertheless, the possibility of recall bias in general, and a gender recall bias of family history in particular, remains. A second potential limitation is that our use of a single FPG value to ascertain undiagnosed diabetes may have resulted in misclassification bias. However, measuring FPG levels is currently the standard method for diagnosing diabetes and has been shown to have higher reliability and lower interindividual variation than other acceptable diagnostic tests. ${ }^{5} \mathrm{~A}$ third limitation is that because we used data from a cross-sectional survey, we were unable to determine whether the associations we found were causal. However, because people with undiagnosed diabetes are by definition unaware of their disease status, they are no more likely than those without diabetes to know the diabetes status of family members. Finally, despite the large overall sample size, some of the subgroups analyzed contain relatively small numbers. Therefore, the prevalence estimates must be interpreted with caution and in the context of the high variability, as evidenced by the corresponding wide CIs.

Family history is increasingly recognized as a powerful, costeffective, and readily available screening tool for detecting common diseases such as diabetes. ${ }^{910,18,25}$ Nevertheless, despite its inclusion in many screening guidelines, family history continues to be underused in both clinical and public health settings, possibly because of a lack of data demonstrating its effectiveness. ${ }^{25}$ The results from this analysis of populationbased, nationally representative survey data provide strong evidence that family history can indeed be an effective diabetes screening tool.

\section{References}

1. Harris MI. Diabetes in America: epidemiology and scope of the problem. Diabetes Care 1998;21 Supplement(Suppl 3):C11-C14.

2. Hogan P, Dall T, Nikolov P. Economic costs of diabetes in the US in 2002. Diabetes Care 2003;26:917-932.

3. Mensah GA, Mokdad AH, Ford E, Narayan KM, et al. Obesity, metabolic syndrome, and type 2 diabetes: emerging epidemics and their cardiovascular implications. Cardiol Clin 2004;22:485-504.

4. Centers for Disease Control and Prevention (CDC). Prevalence of diabetes and impaired fasting glucose in adults-United States, 1999-2000. MMWR Morb Mortal Wkly Rep 2003;52:833-837.

5. American Diabetes Association. Screening for type 2 diabetes. Diabetes Care 2004;27 Supplement(Suppl 1):S11-S14.

6. Eddy DM, Schlessinger L, Kahn R. Clinical outcomes and cost-effectiveness of strategies for managing people at high risk for diabetes. Ann Intern Med 2005;143:251264.

7. Abuissa H, Bel DS, O'Keefe JH, Strategies to prevent type 2 diabetes. Curr Med Res Opin 2005;21:1107-1114.

8. Annis AM, Caulder MS, Cook ML, Duquette D, et al. Family history, diabetes, and other demographic and risk factors among participants of the National Health and Nutrition Examination Survey 1999-2002. Prev Chronic Dis 2005;2:A19.

9. Scheuner MT, Wang SJ, Raffel LJ, Larabell SK, et al. Family history: a comprehensive genetic risk assessment method for the chronic conditions of adulthood. Am J Med Genet 1997;71:315-324.

10. Harrison TA, Hindorff LA, Kim H, Wines RC, et al. Family history of diabetes as a potential public health tool. Am J Prev Med 2003;24:152-159.

11. Gumprecht J, Zychma MJ, Moczulski DK, Gosek K, et al. Family history of end-stage renal disease among hemodialyzed patients in Poland. J Nephrol 2003;16:511-515.

12. Danadian K, Balasekaran G, Lewy V, Meza MP, et al. Insulin sensitivity in AfricanAmerican children with and without family history of type 2 diabetes. Diabetes Care 1999;22:1325-1329.

13. da Silva RC, Miranda WL, Chacra AR, Dib SA, et al. Metabolic syndrome and insulin resistance in normal glucose tolerant Brazilian adolescents with family history of type 2 diabetes. Diabetes Care 2005;28:716-718.

14. Arslanian SA, Bacha F, Saad R, Gungor N, et al. Family history of type 2 diabetes is associated with decreased insulin sensitivity and an impaired balance between insulin sensitivity and insulin secretion in white youth. Diabetes Care 2005;28:115-119.

15. National Center for Health Statistics (NCHS). National Health and Nutrition Examination Survey Data. Atlanta, GA: Centers for Disease Control and Prevention (CDC), 2006.

16. National Health and Nutrition Survey (NHANES). NHANES Analytic Guidelines June 2004. National Center for Health Statistics. Atlanta, GA: Centers for Disease Control and Prevention (CDC), 2004.

17. The Evidence Report. Clinical Guidelines on the Identification, Evaluation, and Treatment of Overweight and Obesity in Adults. 98-4083. Bethesda, MD: National Heart, Lung, and Blood Institute, NIH Publication, 1998.

18. Yoon PW, Scheuner MT, Peterson-Oehlke KL, Gwinn M, et al. Can family history be used as a tool for public health and preventive medicine? Genet Med 2002;4:304-310.

19. Yoon PW, Scheuner MT, Khoury MJ. Research priorities for evaluating family history in the prevention of common chronic diseases. Am J Prev Med 2003;24:128135.

20. National Center for Health Statistics (NCHS). National Health and Nutrition Examination Survey Data. Atlanta, GA: Centers for Disease Control and Prevention (CDC), 2005.

21. Spiegelman D, Hertzmark E. Easy SAS calculations for risk or prevalence ratios and differences. Am J Epidemiol 2005;162:199-200.

22. Hosmer DW, Lemeshow S. Applied Logistic Regression. New York: John Wiley \& Sons, Inc., 2000.

23. Sasse EA. Objective evaluation of data in screening for disease. Clin Chim Acta 2002;315:17-30.

24. Centers for Disease Control and Prevention (CDC). Awareness of family health history as a risk factor for disease-United States, 2004. MMWR Morb Mortal Wkly Rep 2004;53:1044-1047.

25. Rich EC, Burke W, Heaton CJ, Haga S, et al. Reconsidering the family history in primary care. J Gen Intern Med 2004;19:273-280. 